\title{
A IMPORTÂNCIA DA EDUCAÇÃO FINANCEIRA NO CURRÍCULO DA EDUCAÇÃO BÁSICA
}

\author{
Edson Rossi ${ }^{1}$ \\ Ariane Paola Lima Araujo ${ }^{2}$
}

RESUMO: A Educação Financeira conforme será apresentada neste trabalho, tem papel importante em nossa sociedade, e a escola é o elo essencial entre o aluno e o conhecimento. É na escola que serão feitas as experimentações entre a aprendizagem e a realidade vivida pelo aluno. Dessa forma, o presente trabalho foi elaborado visando apresentar um estudo sobre a importância da Educação Financeira, de modo que seja justificado, que esse tema possa ser trabalhado pelos professores durante todo o período em que o aluno estiver cursando a educação básica. Esse é um assunto que já vem sendo levantado por diversos autores, conforme será apresentado neste trabalho. Nos dias atuais, ainda é pouco a relevância que se dá ao tema, mesmo sendo recomendado na BNCC - Base Nacional Comum Curricular. Para a realização deste trabalho foram consultados livros, documentos como a própria BNCC e outras fontes bibliográficas que comprovam a importância desse assunto para a educação dos alunos e a formação de cidadãos críticos e que estejam mais preparados para enfrentar a realidade fora da sala de aula. Kliemann, Silva e Dullius (20iI) ainda reforçam que os alunos precisam ter contato com o aprendizado da Matemática Financeira desde cedo na sala de aula, e que a Educação Financeira tenha sua real significância reconhecida na sociedade, e que através da conquista desse conhecimento os cidadãos venham a se tornar mais prudentes e conscientes diante a realidade.

Palavras-chave: Currículo. Educação Financeira. Educação Básica. Matemática Financeira.

ABSTRACT: Financial Education, as it will be presented in this work, has an important role in our society, and the school is the essential link between the student and knowledge. It is at the school that experiments between learning and the reality experienced by the student will be carried out. Thus, the present work was designed to present a study on the importance of Financial Education, so that it is justified that this topic can be worked on by teachers throughout the period in which the student is attending basic education. This is a subject that has been raised by several authors, as will be presented in this work. Nowadays, there is still little relevance given to the topic, even though it is recommended by the BNCC - Common National Curriculum Base. To carry out this work, books, documents such as the BNCC itself and other bibliographic sources were consulted that

\footnotetext{
${ }^{1}$ Licenciando em Matemática pelo Instituto Federal do Triângulo Mineiro (IFTM), Especialização em Matemática Financeira e Estatística (FUNIP), Especialização em Engenharia de Segurança Contra Incêndio e Pânico (UCAM) e Graduação em Arquitetura e Urbanismo (UNIUBE).

${ }^{2}$ Licencianda em Pedagogia pela UNOPAR, Especialização em Gestão Escolar: Administração, Supervisão e Orientação (UCAM), Especialização em Psicopedagogia Institucional (Universidade Cruzeiro do Sul) e Graduação em Psicologia (UNIUBE).
} 
prove the importance of this subject for the education of students and the formation of critical citizens who are better prepared to face the reality outside the classroom. Kliemann, Silva and Dullius (20II) also reinforce that students need to have contact with the learning of Financial Mathematics from an early age in the classroom, and that Financial Education has its real significance recognized in society, and that through the achievement of this knowledge, citizens will become more prudent and aware of reality.

Keywords: Curriculum. Financial Education. Basic Education. Financial Mathematics.

\section{INTRODUÇÃO}

É fato que no mundo onde vivemos, estar preparado para os imprevistos é sempre importante. Estar capacitado ou pelo menos ter uma boa noção de assuntos sobre finanças, podem futuramente ser uma ferramenta essencial para enfrentarmos quaisquer tipos de dificuldades que venham a surgir. É nessa linha de raciocínio, que esse trabalho pretende ratificar a necessidade do aprendizado e da inserção da Educação Financeira em todo o percurso do aluno na Educação Básica.

Portanto, neste contexto, o objetivo principal deste trabalho é o de analisar a importância do ensino sobre a temática da Educação Financeira frente ao contexto escolar, observando a relevância do tema para a construção do conhecimento do indivíduo.

Para atingir tal objetivo, utilizou-se como recurso metodológico, a pesquisa bibliográfica, com foco qualitativo, utilizando o levantamento do referencial teórico, com base em fontes científicas, livros, revistas, periódicos, sites, dicionários, enfim, diversas literaturas relacionadas ao tema.

A pesquisa bibliográfica foi realizada com o intuito de rever, re-analisar, interpretar e criticar considerações teóricas ou paradigmas, ou ainda criar novos teoremas, com o objetivo de tentar compreender os fenômenos das mais diversas áreas do conhecimento. (PRESTES, 2003).

Nesse sentido, pretende-se responder algumas questões que foram norteadoras para a pesquisa: Como a importância do conhecimento sobre Matemática Financeira tem sobre a Educação Financeira do aluno e o como esse aprendizado pode contribuir para sua vida pós a Educação Básica.

Para o desenvolvimento desse tema, buscou fundamentar o artigo apoiando em estudos produzidos e concebidos por autores como: Bastos (2008), Biaggi (2000), Carvalho 
(2000 e 2006), Costa Junior e Claro (2013), Dal Zot (2015), Gomes (2010), Kimura (2005), Kliemann, Silva e Dullius (2011), Lima e Sá (2010), Luz e Bayer (2013), Mercado (1998), Nogueira e Omodei (2012), Pinheiro, Giambiagi e Gostkorzewicz (1999), Prestes (2003), Rosetti e Schimiguel (201I) e Santos (I995).

\section{DESENVOLVIMENTO}

Em algum momento de nossas vidas, iremos nos deparar diante de alguma situação, onde o conhecimento prévio no campo da Educação Financeira será essencial para que possamos tomar certas decisões. E é partindo de uma dessas premissas, que o assunto no ambiente escolar, deve ser debatido com mais frequência.

Controlar as finanças pode ser o maior desafio que uma pessoa pode encontrar em vida. Toda relação com o bem material, desde a compra de alimentos para a subsistência até na aquisição de um bem valioso, deve ser feito observando um planejamento financeiro.

Pode se destacar o Planejamento Financeiro como item importante e complementar à Educação Financeira, e entendê-la contempla o aprendizado realizado através da Matemática Financeira.

Dal Zot (2015) diz que a Matemática Financeira pertence ao ramo da Matemática Aplicada, e como tal, auxilia no entendimento dos fenômenos da vida real, permitindo assim uma melhor compreensão do comportamento do dinheiro ao longo do tempo. Mas, o comportamento do indivíduo ao lidar com o dinheiro também é outro elemento que precisa ser revisto. Uma vez que ao citar a palavra "Comportamento", é preciso fazer uma relação entre Educação Financeira à outra área de conhecimento, o da Psicologia. Pois, de acordo com Francisco Teloeken na edição Tempo \& Dinheiro, da sua coluna no Jornal Gazeta do Sul, há io anos já relatava que:

Educação financeira não é apenas saber fazer algumas contas, elaborar e cumprir um orçamento doméstico, pesquisar preços, evitar dívidas, poupar e investir, e outras coisas importantes. Se dinheiro fosse como Matemática, nenhum de nós cometeria erros, gastaria mais do que tem, economizaria de menos. Educação Matemática compreende tudo isso e, mais recentemente, com a aproximação da economia e da psicologia, a Economia Comportamental, que quer explicar por que e como as pessoas tomam decisões, aparentemente irracionais ou ilógicas, quando gastam, investem, poupam ou emprestam dinheiro (FRANCISCO, 2oIo, texto digital). 
Talvez um pouco desse comportamento dos brasileiros em relação às finanças, decorre devido ao histórico da economia que o país enfrentou. Só para fazer uma breve recordação, os brasileiros passaram por um grande período de turbulência na economia nos últimos quarenta anos, quando foi submetido a vários planos econômicos. Entre eles estão o Plano Cruzado, Plano Verão, os Planos Collor I e II, que foram implantados com o objetivo de tentar acabar com a hiperinflação que assolou a vida das pessoas por mais de is anos. Desde o início dos anos I980 até a implantação do Plano Real em 1994, o país passou por grande estagnação e desiquilíbrios econômicos. Até a estabilidade da moeda brasileira com o controle da hiperinflação que corroía o poder de compra dos brasileiros, a superinflação chegou a bater índices anuais na década de 1980 de $233,5 \%$ e na década seguinte entre os anos de 1.990 e I.999, onde a inflação anual chegou a estratosférica marca de 499,2\%. Apenas após o advento do Real em 1.994 esses índices diminuíram significativamente (PINHEIRO; GIAMBIAGI; GOSTKORZEWICZ, 1999).

Com a diminuição do poder de compra ao longo dos dias, ocasionado pela hiperinflação, impulsionava nas pessoas o hábito de estocar alguns produtos, antes que o dinheiro perdesse valor. No meio disso, percebe também que não havia um parâmetro para o preço dos produtos, pois os valores eram remarcados diariamente. Sobre o fato de "comprar logo", Carvalho (200o) relata que:

[...] elevada propensão a consumir da grande massa de pessoas pobres. A memória das experiências passadas aconselha a "comprar logo", antes que os preços subam e os produtos desapareçam, e estimula o endividamento, pois o retorno da inflação, tido como certo, desvalorizará as prestações e elevará os salários. (CARVALHO, 200o, p.125).

Essa cultura impulsiva de consumo alinhada ao poder de compra da moeda atual, fez com que muitos brasileiros entrassem no mundo do endividamento, auxiliado pelas facilidades. E alguns fatores impulsionaram esse endividamento dos brasileiros: como a demanda até então reprimida e atrelada a superinflação; e a própria estabilização dos preços que propiciou a facilidade de consumo. Ainda sobre a dissolução da hiperinflação, Carvalho (2006) complementa que:

[...] é levada em conta a condição propícia ao consumo após a estabilização dos preços. Com o fim do imposto inflacionário, a renda dos cidadãos aumenta o seu poder de compra, após anos de inflação. Porém, o medo de que a inflação voltasse e que os preços tornassem a subir, causou a euforia no consumo imediato (CARVALHO, 2006). 
É nesse sentido que este trabalho vem apresentar a importância do conhecimento sobre a temática da Educação Financeira na Educação Básica. Para que os alunos possam exercitar esse conhecimento com o auxílio dos professores no ambiente escolar, é importante utilizar como parâmetro a realidade em que vivem.

A escola é um espaço de multiplicidade, diversidade e diferença, onde está presente relações de saber e poder baseadas no que é ensinado e como é ensinado. (GOMES, 2010). É pensando dessa forma, onde o aprendizado realizado no ambiente escolar deve ter uma relação com as vivências do aluno fora da sala de aula, ou seja, deve ter uma ligação com sua realidade. Logo, a escola é o melhor lugar onde o aluno terá uma identificação com a realidade em que vive e o que deverá ser aprendido na escola.

Dentro dessa relação temos nosso agente transformador, o professor, e do outro lado, os alunos, que são transformados pelo que lhe são ensinados.

De acordo com Kliemann, Silva e Dullius (20II), defendem que a Matemática Financeira é de fundamental importância para a formação de cidadãos críticos e conhecedores dos seus deveres e direitos.

No trabalho realizado pelas autoras, intitulado "Relevância da Matemática Financeira no Ensino Fundamental”, praticamente concebido através de análises de livros didáticos das escolas municipais das cidades de Taquari e Rio Pardo, no estado do Rio Grande do Sul, e em documentos consultados à época, como a LDB (Lei de Diretrizes e Base da Educação) e os PCNs ( Planos Curriculares Nacionais), recomendam que o estudo da Matemática Financeira deveria ser feito desde o Ensino Fundamental, com o objetivo de conscientizar as pessoas quanto à importância desse conhecimento em seu cotidiano.

Nesse caso em particular, as autoras apontam uma contradição, pois o conteúdo sobre Matemática Financeira é até mencionado nos livros didáticos, inclusive com problemas de fácil compreensão, mas o que acontece é que não há uma absorção do aprendizado pelo aluno.

Nogueira e Omodei (2012) ainda concluem que ensinando os jovens desde pequenos, fazendo-os participar tanto no orçamento familiar quanto na sala de aula, é de grande importância para que as crianças cresçam aprendendo a ter um pensamento mais consciente ao fazer uso do dinheiro. 
A Educação Financeira também não deve ficar restrita somente às crianças, a instrução desse conhecimento deve ser transmitida tanto para jovens como para adultos. Pois, conforme mencionado por Bastos (2008), o assunto deve ser trabalhado com esses educandos, levando em consideração no processo de aprendizagem, a situação econômica dos estudantes, proporcionando assim uma melhor compreensão associada às suas realidades.

A ideia de considerar as vivências dos alunos no aprendizado de forma geral, também era mencionada por Paulo Freire, que defendia a ideia do aluno já adulto, possuir um currículo diferente dos alunos mais jovens, pois entendia que o conhecimento empírico, ou seja, as experiências adquiridas durante a vida, deveriam ser consideradas no processo de ensino-aprendizagem. (FREIRE, 1997)

É nesse contexto que devemos pensar a Educação Financeira, onde pudesse estar acessível a todas as idades e níveis de ensino. Para isso, é importante pensar um Currículo mais amplo, onde o assunto possa ter uma relação mais próxima com a realidade dos alunos, já que vivemos em uma sociedade capitalista e o conhecimento desse assunto é fundamental.

Bastos (2008), acrescenta justamente isso, lembrando que estamos inseridos em uma cultura capitalista, onde transações comerciais e financeiras são as bases da nossa sociedade, e o tema sobre Educação Financeira não pode estar ausente do Currículo escolar.

Como é um assunto muito importante para o aprendizado do aluno, é necessário considerar algumas formas de tornar o ensino mais atraente e menos desgastante para o estudante. No processo de ensino-aprendizagem é essencial envolver o aluno no desenvolvimento das atividades. Para isso, tornar o aprendizado em Matemática Financeira, uma atividade mais prazerosa para os alunos, é importante considerar algumas estratégias, que podem ser adotadas para explorar mais esse conhecimento de forma lúdica. Entre alguns exemplos na realização das atividades, podem ser ofertados trabalhos realizados com jogos. Kimura (2005) ao sugerir atividades utilizando jogos, cita que esse tipo de exercício pode ser desafiador e ainda despertar a curiosidade do aluno, consequentemente tornando-o mais interessado no processo de ensino-aprendizagem e engajado na construção dos conceitos matemáticos. 

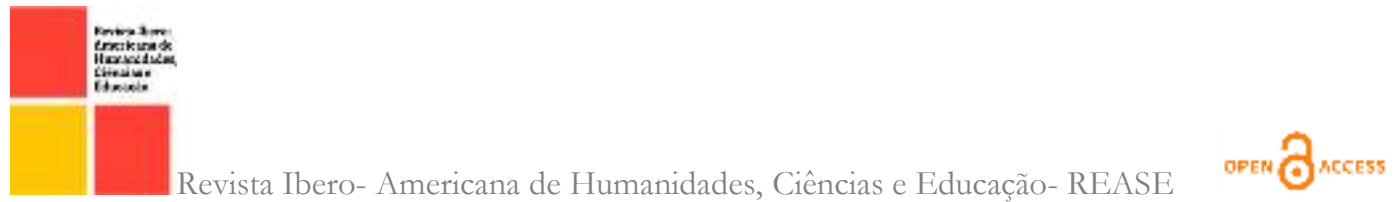

Entre as preocupações que não devem estar de fora nas discussões sobre a importância da Educação Financeira para a formação dos jovens é a inserção no Mercado de Trabalho. Justificado pelo fato dos jovens estarem fazendo a transição para a vida adulta e consequentemente para a vida profissional. Em geral o que se espera, é que o Mercado de Trabalho, faça uma seleção tendo em vista os profissionais mais capacitados, para que correspondam às atividades que esses profissionais serão designados. Ao analisar dessa forma, a Educação Financeira é preponderante e também a base de todo um desenvolvimento, caso contrário a falta desse conhecimento pode trazer certos aborrecimentos. Rosetti e Schimiguel (20II), fazem referência ao fato que caso o jovem não tenha conhecimento básico nas operações financeiras, poderá enfrentar problemas ao ingressar no Mercado de Trabalho. E são justamente esses empecilhos que dificultam a inserção do jovem ao ingressar na vida profissional, pois a concorrência ao Mercado de Trabalho está cada vez mais exigente quanto à sua qualificação.

Visto que é muito importante o incremento da Educação Financeira no cotidiano escolar, principalmente pelo fato de capacitar o jovem para o mercado de trabalho, isso só deixa mais evidente a necessidade desse conhecimento estar bem alinhado com Ensino Médio, pois é neste momento que o jovem está se encaminhando para o Mercado de Trabalho. $\mathrm{Na}$ teoria o jovem ingressaria na vida profissional assim que terminasse o Ensino Médio, e pensando dessa forma o trabalho em sala de aula deve estabelecer uma relação entre o conhecimento aprendido em sala e as vivências do cotidiano. Logo, deve se ter uma prática do ensino da Matemática Financeira, ou melhor, uma imersão ao mundo da Educação Financeira desde os anos iniciais do Ensino Fundamental.

Detalhe que é mencionado por Lima e Sá (2010) ao apontar que as disciplinas com esse conteúdo devem estar atreladas desde os Anos Iniciais do Ensino Fundamental, onde o ensino pudesse ter uma relação adequada com a idade do educando, utilizando e explorando o lúdico, fazendo simulações de compras e vendas, histórias em quadrinhos, preenchimento de documentos sobre o tema de finanças, etc.

De acordo com Costa Junior e Claro (2013), desde 2010 veem sendo implementado nas escolas públicas, conteúdo sobre Educação Financeira nas matrizes curriculares dos estudantes do Ensino Fundamental e do Ensino Médio, em mais de 900 escolas pelo país, através do projeto de Estratégia Nacional de Educação Financeira (Enef). A proposta tinha 
o caráter de elevar o nível de conhecimento sobre Educação Financeira na população brasileira. Atualmente, na BNCC - Base Nacional Comum Curricular, desde que foi aprovado o assunto é pouco mencionado, diferente da expectativa que foi criada em 2009 com o lançamento do Enef.

Ressaltando que na BNCC, temáticas como: Saúde, Vida Familiar e Social, Trabalho, Ciência e Tecnologia, Diversidade Cultural, Educação para o Consumo, Educação Financeira e Fiscal são contempladas em habilidades dos componentes curriculares, mencionando que devem ser trabalhadas de forma contextualizada, de acordo com as especificidades de cada sistema de ensino e suas respectivas escolas. (BRASIL, 20I8, p.20)

Sobre o Ensino Fundamental - Anos Finais, já a BNCC ao fazer referência sobre alguns conteúdos relacionados à Educação Financeira, podem ser observados, onde são cobrados dos alunos na realização de atividades envolvendo cálculo de porcentagem, porcentagem de porcentagem, taxa de juros, inflação, descontos de acréscimos e até aplicações financeiras (como rentabilidade, liquidez de um investimento) e cálculo de impostos, podendo incrementar na realização das aulas, o uso de tecnologias digitais. (BRASIL, 2018, p.269)

Aliás, as tecnologias digitais propiciam ao aluno explorar mais o conhecimento estudado, tanto na própria matemática como em outras ciências. Desse modo, pode ser citado Mercado (1998), fazendo referência sobre a utilização das novas tecnologias como um meio de produzir conhecimento no ambiente escolar, diz que:

\begin{abstract}
O objetivo de introduzir novas tecnologias na escola é para fazer coisas novas e pedagogicamente importantes que não se pode realizar de outras maneiras. $O$ aprendiz, utilizando metodologias adequadas, poderá utilizar estas tecnologias na integração de matérias estanques. A escola passa a ser um lugar mais interessante que prepararia o aluno para o seu futuro. A aprendizagem centra-se nas diferenças individuais e na capacitação do aluno. (MERCADO, 1998, p.6).
\end{abstract}

\title{
CONCLUSÃO
}

Com base nos levantamentos realizados, é possível perceber que a Educação Financeira ainda caminha a passos lentos, que mesmo com os programas de Governo e o que é cobrado na BNCC ainda precisam ser melhor apreciados. É um tema importante que tem relação direta com a vida das pessoas, pois na sociedade brasileira ainda é muito 
carente desse conhecimento, haja visto o endividamento da civilização e o enfrentamento diante das crises financeiras e as transições de planos econômicos como medida de salvar o país de uma inflação que já teve proporções colossais.

É importante que as práticas pedagógicas devem ser orientadas e os conteúdos didáticos devem estar alinhados conforme a realidade que os alunos vivem. $\mathrm{O}$ aprendizado em sala de aula deve ter uma relação paralela e próxima com o cotidiano, e devem ser considerados no processo de ensino-aprendizagem todo o contexto exigido pela sociedade. Citando o que escreve Biaggi (200o), "não é possível preparar alunos capazes de solucionar problemas ensinando conceitos matemáticos desvinculados da realidade, ou que se mostrem sem significado para eles, esperando que saibam como utilizá-los no futuro".

Deixando claro que o aprendizado sobre Educação Financeira deve estar inserido desde os Anos Iniciais do Ensino Fundamental, para que o aluno ao chegar no Ensino Médio viva a transição para a vida profissional mais capacitado para exigências do Mercado de Trabalho e da vida adulta que lhe espera.

O ambiente escolar deve servir de oficina e de experimentação para os desafios que esses alunos irão enfrentar, logo o Currículo deve fazer perceber a necessidade de incorporar a Educação Financeira em sala de aula.

A Educação Financeira possibilita ao indivíduo ter uma visão mais crítica e analítica das suas decisões, pois muitas delas deverão comprometer muitos anos de suas vidas. E estar apto e mais preparado para esses momentos, pode ser de grande importância para se evitar alguns transtornos durante a vida.

O tema sobre Educação Financeira, ao serem introduzidas na escola, precisam passar por uma adequação aos propósitos educativos, os professores devem ser capacitados ao ministrar esse conhecimento utilizando recursos e métodos que propiciem um ensino adequado à idade e realidade dos estudantes, e para isso deve haver um suporte de todos que compõem o núcleo escolar.

O conteúdo sobre Educação Financeira deve estar entrelaçado com as demais disciplinas e não ficar restrita apenas a Matemática, pois ao se trabalhar a interdisciplinaridade, realiza a imersão do aluno dentro de outras áreas de conhecimento, consequentemente provocando e instigando quanto às suas aplicações. 
Portanto, deve se ter um olhar mais amplo sobre a temática da Educação Financeira, preparando melhor tanto professores quanto o Currículo escolar, para que os alunos ao deixar o Ensino Médio, se deparem com uma vida adulta e profissional melhor preparados.

\section{REFERÊNCIAS}

BASTOS, Antônio Sergio Abrahão Monteiro. Noções de porcentagem, de desconto e de acréscimo na educação de jovens e adultos. In. Pesquisa em Educação Matemática: um encontro entre a teoria e a prática. São Carlos: Pedro e João Editores, 2008.

BIAGGI, G. V. Uma nova forma de ensinar matemática para futuros administradores: uma experiência que vem dando certo. Ciências da Educação. Lorena-SP, v. 2, n. 2, 2000.

BRASIL. Ministério da Educação. Secretaria da Educação Básica. Base nacional comum curricular. Brasília, DF, 2018. Disponível em: 〈http://basenacionalcomum.mec.gov.br/abase>. Acesso em: is jan. 2021;

BRASIL. Lei de Diretrizes e Bases da Educação Nacional. Lei n. 9394 de 20 de dez. de 1996. Estabelece as diretrizes e bases da Educação Nacional. Brasília: 1996. Disponível em: 〈http://www.planalto.gov.br/ccivil_03/LEIS/L9394.htm> Acessado em: I5 jan. 202I

CARVAlHO, Carlos Eduardo. As origens e a gênese do Plano Collor. Nova econ., Belo Horizonte, v. I6, n. I, p. IOI-134, Abril. 2006 . Disponível em: $<$ http://www.scielo.br/scielo.php?script=sci_arttext\&pid=So10363512006000100003\&lng $=$ en $\&$ nrm=iso; Acesso em is jan. 2021.

CARVALHO, Carlos Eduardo. O Plano Collor no debate econômico brasileiro. Pesquisa \& Debate, Sp, v. II, n. I, p.II2-I5I, 2000. Disponível em: 〈https://revistas.pucsp.br/index.php/rpe/article/view/Irg91/8683〉. Acesso em: is jan. 2021. 
COSTA JUNIOR, Cales Alves da; CLARO, Olga Maria Barreiro. Educação Financeira: um instrumento de consciência econômica. Em Teia: Revista de Educação Matemática e Tecnológica Iberoamericana, Recife, v. 4, n. 3, p. I-25, 2013. Disponível em: https://periodicos.ufpe.br/revistas/emteia/article/view/2220/I792. Acesso em: I5 jan. 202I.

DAL ZOT, W. Matemática Financeira. Porto Alegre: Editora UFRGS .20o6.

FREIRE, P. Pedagogia do oprimido. Rio de Janeiro: Paz e Terra, 1997.

GOMES, Vitor. Fundamentos filosóficos e sociológicos da educação. Vitória: Ifes, 2010. 8op.

KIMURA, Cecília Fukiko Kamei. O jogo como ferramenta no trabalho com números negativos: um estudo sob a perspectiva da epistemologia genética de jean Piaget. Tese (Doutorado em Educação). Pontifícia Universidade Católica de São Paulo. São Paulo, 2005 .

KLIEMANN, Geovana Luiza; SILVA, Patrícia Fernanda; DULLIUS, Maria Madalena. Relevância da Matemática Financeira no Ensino Fundamental. Revista Destaques Acadêmicos, Lajeado, RS, ano 3, n. 4, 2011.

LIMA, C. B; SÁ, L. P. Matemática financeira no ensino fundamental, Revista TECCEN Vol. 3, n. I, abril de 2oro. Disponível em: $\langle$ http://www.uss.br/web/revista_informativo5/artigoo3.pdf $\rangle$. Acesso em: I5 jan.202I.

LUZ, L. H; BAYER, A. Matemática Financeira Na Educação Básica. In: VI Congresso Internacional de Ensino da Matemática. 2013, Canoas. Disponível em: 〈http://www.conferencias.ulbra.br/index.php/ciem/vi/paper/viewFile/942/r79〉. Acesso em I5 jan. 202I. 
MERCADO, L. P. L. Formação docente e novas tecnologias. 1998. Disponível em: <http://www.educacional.com.br/upload/dados/materialapoio/71170ool/5275731/FORMA $\% \mathrm{C}_{3} \% 87 \% \mathrm{C}_{3} \% 83 \mathrm{O}$ _DOCENTE_E_NOVAS_TECNOLOGIAS.pdf >. Acesso em: is jan. 2021.

NOGUEIRA, Lays Almeida; OMODEI, Leticia B. Celeste. A Educação Matemática Financeira no Ensino Fundamental: uma proposta de ensino. Paraná, 2012. Disponível em: < http://www.fap.com.br/forum_2012/forum/pdf/Exatas/Poster/ResExaPoi.pdf >. Acesso em: 15 jan. 2021.

PINHEIRO, Armando Castelar; GIAMBIAGI, Fabio; GOSTKORZEWICZ, Joana. O Desempenho Macroeconômico do Brasil nos Anos 90. A Economia Brasileira nos Anos 9o, Rio de Janeiro, v. I, n. I, p.II-4I, jan. 1999. Disponível em: <https://web.bndes.gov.br/bib/jspui/bitstream/1408/2972/I/1999_A economia brasileira nos anos 90_P.pdf >. Acesso em: is jan. 2021.

PRESTES, Maria Luci de Mesquita. A pesquisa e a construção do conhecimento: do planejamento aos textos, da escola à academia. 2 ed. São Paulo: Rêspel, 2003.

ROSETTI , Hélio Junior; SCHIMIGUEL, Juliano. Educação Matemática Financeira: uma análise comparativa dos modelos matemáticos em bibliografia adorada no ensino médio. II Encontro Goiano de Educação Matemática. Anais do II Encontro Goiano de Educação Matemática, Goiás, 2009.

SANTOS, Anelise Peixoto dos, 1995 - Inflação na era Collor: fatores geradores e desdobramentos / Anelise Peixoto dos Santos, Bianca Fermino Sertori. - Limeira, SP: [s.n], 2017.

SUL, Jornal Gazeta. Educação Financeira nas Escolas. Edição Tempo \& Dinheiro. Edição II/o9/2010. Disponível em: <http://www.gaz.com.br/gazetadosul/noticia/241232educacao_financeira_nas_escolas. html $>$. Acesso em: 15 jan. 2021. 